\title{
PENGARUH KOMPOSISI MEDIA TANAM TERHADAP PERTUMBUHAN SETEK EMPAT KLON UBI KAYU (Manihot esculenta Crantz)
}

\section{EFFECTS OF MEDIA COMPOSITIONS ON GROWTH OF FOUR CLONES OF CASSAVA STEM CUTTINGS (Manihot esculenta Crantz)}

\author{
Fitri Yelli ${ }^{1}$, Akari Edy dan Setyo Dwi Utomo ${ }^{2}$,Topan Kurniawan Giannini ${ }^{1}$ \\ ${ }^{1}$ Jurusan Agroteknologi, Fakultas Pertanian, Universitas Lampung, Bandar Lampung, Indonesia \\ ${ }^{2}$ Jurusan Agronomi dan Hortikultura Fakultas Pertanian, Universitas Lampung, Bandar Lampung, Indonesia \\ *Email:fitri.yelli79@gmail.com
}

* Corresponding Author, Diterima: 1 Feb. 2021, Direvisi: 19 Apr. 2021, Disetujui: 8 Mei 2021

\begin{abstract}
The purpose of this research was to determine (1) the media composition that support growth of cassava cuttings, (2) to find cassava clone which shows the best growth on the treatment medium and (3) to observe whether the response of cassava cuttings to the composition of the planting medium was influenced by the clones used. The research was conducted at the Greenhouse of Faculty of Agriculture, University of Lampung from April 2020 to June 2020. The study was arranged in a completely randomized design with 3 replications. The treatments were factorially arranged, i.e planting media (soil + sand + rice husk and soil+sand+compost) and 4 clones (UJ-3, UJ-5, BW1, Unila UK-1). The results showed that (1) The media compositions resulted in the same growth of four clone of cuttings (2) Types of clone did not significantly influence growth on the media composition tested.
\end{abstract}

Keywords: Cassava, clones, compost, organic materials, rice husk.

\begin{abstract}
ABSTRAK
Penelitian ini bertujuan untuk menentukan komposisi media tanam yang tepat untuk pertumbuhan setek ubi kayu, menentukan klon ubi kayu yang memiliki pertumbuhan terbaik dan mengetahui apakah respon setek ubi kayu terhadap komposisi media tanam ditentukan oleh klon yang digunakan. Penelitian dilaksanakan di Rumah Kaca Fakultas Pertanian, Universitas Lampung dari bulan April 2020 sampai bulan Juni 2020. Penelitian disusun secara faktorial dalam rancangan acak lengkap (RAL) dengan 3 ulangan. Faktor pertama adalah komposisi media (tanah+pasir+sekam padi dan tanah+pasir+kompos) dan faktor kedua adalah klon (UJ-3, UJ-5, BW1, Unila UK-1). Hasil penelitian menunjukkan (1) komposisi media menghasilkan pertumbuhan yang sama. (2) Klon memberikan respons yang sama terhadap komposisi media.
\end{abstract}

Kata kunci : Bahan organik, klon, kompos, sekam padi, ubi kayu.

\section{PENDAHULUAN}

Ubikayu(Manihot esculenta Crantz) mempunyai peran penting dalam industri. Permintaan ubi kayu mengalami peningkatan seiring dengan program pemerintah untuk menggunakan sumber energi alternatif yang berasal dari hasil pertanian, seperti biodiesel dan bioetanol, serta diversifikasi pangan lokal (Sundari, 2010). Manfaat ubi kayu sangat banyak, antara lain 
sebagai pangan, pakan ternak, serat, bioethanol, biodiesel, pupuk dan lain-lain (Atmawinata dkk, 2011). Berdasarkan hal tersebut maka permintaan ubi kayu diprediksi akan meningkat.

Seiring dengan peningkatan tersebut maka akan dibutuhkan ketersediaan bibit secara terus-menerus. Untuk memenuhi kebutuhan bibit tersebut, kendala dalam produksi bibit ubi kayu terutama bibit klon-klon unggul dapat diatasi dengan perbanyakan tanaman misalnya secara in vitro (Ardian, 2010 atau melalui setek di lapangan atau rumah kaca. Penanaman setek ubi kayu di rumah kaca dapat digunakan sebagai sarana untuk mendapatkan media yang cocok untuk mendukung pertumbuhan setek, yaitu yang mampu menginduksi munculnya akar dan tunas dalam waktu yang lebih cepat dan mampu mendukung pertumbuhan vegetatif yang baik, yang berlaku bagi banyak klon ubi kayu. Penanaman di rumah kaca juga dapat digunakan untuk menghasilkan eksplan dengan tingkat kontaminasi yang lebih rendah dibandingkan dengan tanaman yang berasal dari lapangan. Sumber eskplan yang biasa digunakan untuk tanaman ubi kayu dalam perbanyakan secara in vitro yaitu bagian buku dan tunas meristem (Ardian, 2010). Untukpeningkatan jumlah sumbereksplan yang banyak dan sehat maka diperlukan tanaman yang tumbuh sehat atau bebas penyakit, salah satunya dengan penggunaan media tanam yang tepat (Sundari, 2010).

Menurut Roni (2015), media tanam adalah media yang digunakan untuk menumbuhkan tanaman, tempat akar atau bakal akar akan tumbuh dan berkembang. Tanaman yang diperbanyak dengan cara penyetekan umumnya ditanam pada media yang dapat menunjang pembentukan akar dan tunas tanaman.
Menurut Sundari (2010), tanaman ubi kayu dapat tumbuh baik di tanah yang bertekstur remah, gembur, tidak terlalu liat dan tidak terlalu poros.

Bahan-bahan untuk media tanam dapat dibuat dari bahan tunggal atau kombinasi dari beberapa bahan seperti kompos dan sekam padi mentah. Media campuran yang menggunakan kompos dapat memperbaiki struktur, tekstur, dan lapisan tanah, terutama dalam meningkatkan dan menjaga kesuburan tanah serta mengurangi penggunaan pupuk anorganik. Selain untuk memperbaiki kondisi tanah, kompos juga diharapkan dapat meningkatkan daya tahan tanaman dari serangan hama dan penyakit, serta menambah unsur hara untuk tanaman (Handayanto, 2017).

Sekam padi berasal dari kulit biji padi (Oryza sativa) yang sudah digiling atau belum. Sekam padi mentah digunakan sebagai campuran media tanam karena dapat memperbaiki sistem aerasi dan drainase media tanam. Kelebihan sekam padi mentah yaitu mudah mengikat air, sumber kalium $(\mathrm{K})$ bagi tanaman, dan menyebabkan media tidak mudah menggumpal atau memadat sehingga akar tanaman dapat tumbuh sempurna. Mengingat pentingnya komposisi media tanam, maka perlu dilakukan penelitian mengenai komposisi media tanam. Penelitian ini bertujuan untuk menentukan komposisi media tanam terhadap pertumbuhan setek beberapa klon ubi kayu.

\section{BAHAN DAN METODE}

Penelitian dilaksanakan di Rumah Kaca Fakultas Pertanian, Universitas Lampung. Penelitian dilakukan dengan menggunakan rancangan acak lengkap (RAL). Perlakuan disusun secara faktorial 
(2x4). Faktor pertama adalah campuran media tanam (m) yang terdiri yaitu campuran tanah, pasir dan sekam padidengan perbandingan 4:2:1(m1) dan campuran media tanam tanah, pasir, dan kompos dengan perbandingan 4:2:1 (m2). Faktor kedua adalah jenis klon (k) yang terdiri atas empat klon yaitu klon UJ-3 (k1), klon UJ-5 (k2), klon BW-1 (k3) dan klon Unila UK-1 (k4).

Setiap perlakuan diulang tiga kali yang terdiri atas 4 setek per ulangan, sehingga diperlukan 96 setek ubi kayu. Homogenitas ragam antar perlakuan diuji dengan uji Barlett dan aditivitas data diuji dengan uji Tukey. Apabila kedua asumsi ini terpenuhi maka dilakukan analisis ragam (uji F). Apabila uji F signifikan dilanjutkan dengan pemisahan nilai tengah menggunakan beda nyata terkecil (BNT). Semua pengujian dilakukan dengan taraf nyata $5 \%$.

Media tanam yang digunakan adalah tanah, pasir, sekam padi dan kompos. Semua media tanam disterilkan dengan cara dikukus selama 30 menit. Media yang sudah disterilisasi dicampurkan dengan perbandingan $4: 2: 1=\mathrm{V}: \mathrm{V}: \mathrm{V}$ hingga homogen. Selanjutnya, kedua campuran media tersebut dimasukkan ke dalam polybag berukuran $10 \mathrm{~kg}$.

Setek yang digunakan diambil dari setek batang ubi kayu klon UJ-3, UJ-5, BW-1 dan Unila-UK1 yang telah berumur di atas 10 bulan. Setek dipotong-potong berukuran $\pm 30 \mathrm{~cm}$ dan bagian basal batang dipotong dengan kemiringan $45^{\circ}$. Setelah setek ubi kayu siap, setek ditanam di polybag. Dalam satu polybag terdapat 4 setek ubi kayu dengan klon sesuai perlakuan.

Pengamatan dilakukan setiap minggu, dan data yang diolah adalah data pada minggu ke 7 setelah tanam (MST). Variabel pengamatan dalam penelitian ini adalah waktu bertunas, persentase tumbuh, panjang tunas, jumlah buku pada tunas, jumlah daun, jumlah akar, panjang akar, bobot basah akar dan bobot kering akar.

Pemeliharaan meliputipenyiraman, pemupukan dan pengendalian gulma. Penyiraman dilakukan dua hari sekali dengan volume air yang sama tiap perlakuan, agar kebutuhan air untuk tanaman dapat terpenuhi dengan baik. Pemupukan dilakukan pada saat 3 MST (minggu setelah tanam) menggunakan pupuk NPK 1616-16 dengan dosis 5 gr tiap polybag. Penyiangan gulma dilakukan secara manual.

\section{HASIL DAN PEMBAHASAN}

Hasil penelitian menunjukkan bahwa komposisi media tanam dan jenis klon tidak berpengaruh nyata terhadap semua variabel yang diamati. Tetapi, pengaruh komposisi media tanam terhadap jumlah akar dan bobot kering akar dipengaruhi oleh jenis klon (Tabel 1).

Pada penelitian ini, rata rata setek bertunas antara $4-8$ hari setelah tanam. Klon Unila UK-1 memiliki waktu bertunas tercepat dibandingkan klon lainnya pada semua perlakuan komposisi media tanam, yaitu 4 hari setelah tanam (HST). Setek klon UJ-5 pada semua perlakuan komposisi media tanam mempunyai waktu bertunas paling lambat dibandingkan dengan perlakuan lainnya, yaitu pada 8 HST (Tabel 2). Salah satu faktor yang mempengaruhi waktu bertunas adalah faktor internal seperti kandungan hormon endogen dari setiap klon yang digunakan. Kandungan sitokinin yang lebih tinggi dibandingkan auksin dapat menyebabkan pertumbuhan tunas lebih cepat. Hal ini sejalan dengan penelitian Lubis (2017), bahwa konsentrasi sitokinin yang lebih tinggi dengan perlakuan 
Tabel 1. Rekapitulasi analisis ragam data penelitian pengaruh komposisi media tanam terhadap pertumbuhan empat klon setek ubi kayu (Manihot esculenta Crantz).

\begin{tabular}{clccc}
\hline No & \multicolumn{1}{c}{ Variabel } & Media $(\mathrm{M})$ & Klon $(\mathrm{K})$ & $\mathrm{M}$ \\
\hline 1 & Panjang Tunas & tn & tn & tn \\
2 & Jumlah Daun & tn & tn & tn \\
3 & Jumlah Buku & tn & tn & tn \\
4 & Jumlah Akar & tn & tn & tn \\
5 & Panjang Akar & tn & tn & tn \\
6 & Bobot Segar Akar & tn & tn & $*$ \\
7 & Bobot Kering Akar & tn & tn & \\
\hline
\end{tabular}

Keterangan: $*$ = berbeda nyata pada taraf $\alpha 5 \%$; $\mathrm{tn}=$ tidak berbeda nyata pada taraf $\alpha 5 \%$

Tabel 2. Pengaruh komposisi media tanam terhadap waktu bertunas dan persentase tumbuh empat klon ubi kayu.

\begin{tabular}{llccc}
\hline Komposisi media tanam & \multicolumn{1}{c}{ Klon } & $\begin{array}{c}\text { Waktu bertunas } \\
\text { (periode pertama) }\end{array}$ & $\begin{array}{c}\text { Waktu bertunas } \\
(50 \% \text { bertunas })\end{array}$ & $\begin{array}{c}\text { Persentase daya } \\
\text { tumbuh }\end{array}$ \\
\hline Tanah+Pasir+ Sekam & & HST (hari setelah tanam) & Persen \\
& UJ-3 & 4 & 8 & 100 \\
& UJ-5 & 8 & 8 & 100 \\
& BW-1 & 6 & 8 & 100 \\
& Unila UK-1 & 4 & 4 & 100 \\
\hline \multirow{5}{*}{ Tanah+Pasir+ Kompos } & UJ-3 & 4 & 7 & 100 \\
& UJ-5 & 8 & 9 & 100 \\
& BW-1 & 5 & 9 & 100 \\
& Unila UK-1 & 4 & 4 & 100 \\
\hline
\end{tabular}

berbagai komposisimediatanam menunjukkankecepatan okulasi ubi kayu lebih cepat, selisihnya yaitu 0,5 HST hingga 3,42 HST. Sehingga diduga bahwa setek klon Unila UK-1 yang digunakan mempunyai konsentrasi sitokinin lebih tinggi dibandingkan klon lainnya.

Pengamatan terhadap persentase daya tumbuh setek tanaman ubikayu menunjukkan bahwa semua klon tanaman yang ditumbuhkan pada semua media yang digunakan mampu tumbuh hingga $100 \%$ pada saat tanaman berumur 2 MST (Tabel 2). Daya tumbuh setek sangat erat kaitannya dengan cadangan makanan dan asal bahan setek. Pada penelitian ini menggunakan batang tengah sebagai sumber bahan setek. Menurut Roja (2009), setek bagian tengah mempunyai kandungan cadangan makanan yang cukup. Sejalan dengan penelitian Ratnasari dkk (2014), bahwa penggunaan bahan tanam yang berasal dari setek tengah menghasilkan tinggi tanaman lebih tinggi (169,7 $\mathrm{cm})$ dibandingkan asal bahan setek pangkal $(157 \mathrm{~cm})$ dan ujung $(135 \mathrm{~cm})$.

Hasil penelitian menunjukkan bahwa kombinasi penggunaan media tanam dan penggunaan klon yang berbeda memberikan pengaruh yang tidak berbeda nyata pada variabel pengamatan panjang tunas, jumlah daun, jumlah buku, panjang akar dan bobot basah akar (Tabel3). Hal tersebut menunjukkan bahwa klon yang digunakan memiliki potensi pertumbuhan yang sama dan mampu beradaptasi pada lingkungan yang berbeda. Sejalan dengan penelitian Ismayani (2016), bahwa penanaman ubi kayu genotipe Roti,Adira 1 dan 
Malaysia pada umur 8 MST tidak menunjukkan perbedaan tinggi tanaman yaitu berturut - turut 107,64 $\mathrm{cm}, 110,44 \mathrm{~cm}$ dan 101,33 cm. Meskipun memiliki potensi pertumbuhan yang sama tapi tetap ada perbedaan pada genotipnya. Perbedaan tersebut ditunjukkan pada variabel jumlah akar dan bobot kering akar.

Hasil penelitian menunjukkan bahwa adanya interaksi antara komposisi media tanam dan jenis klon yang digunakan pada variabel jumlah akar (Tabel 4). Menurut Kusuma dkk (2013) inisiasi akar sangat dipengaruhi oleh ruang pori pada tanah. Nilai porositas pada tanah menggambarkan persentase total pori dalam tanah. Klon UJ-5 yang ditanam pada komposisi media tanam tanah: pasir : kompos menunjukkan jumlah akar tertinggi (44,50 helai) dibandingkan media tanam tanah : pasir : sekam padi (16,50 helai). Hal tersebut menunjukkan bahwa UJ-5 menghendaki media tanam yang tidak terlalu poros. Sedangkan, Unila UK-1 yang ditanam pada media tanam tanah : pasir : sekam padi menghasilkan jumlah akar tertinggi (41,50 helai) dibandingkan media tanah : pasir : kompos $(26,50$ helai). Hal tersebut menunjukkan bahwa Unila UK-1 menghendaki media tanam yang lebih bersifat poros.

Tabel 3. Pengaruh komposisi media tanam terhadap panjang tunas, jumlah daun, jumlah buku, panjang akar dan bobot basah akar setek empat klon ubi kayu.

\begin{tabular}{cccccc}
\hline Perlakuan & Panjang Tunas & Jumlah Daun & Jumlah Buku & Panjang Akar & $\begin{array}{c}\text { Bobot Basah } \\
\text { Akar }\end{array}$ \\
\hline Tanah+pasir+sekam & $(\mathrm{cm})$ & (helai) & (buah) & (cm) & $(\mathrm{g})$ \\
UJ-3 & & & & & \\
UJ-5 & 58,70 & 11,00 & 12,94 & 21,15 & 2,75 \\
BW-1 & 61,72 & 8,75 & 10,75 & 21,30 & 5,20 \\
Unila UK-1 & 44,32 & 10,33 & 12,33 & 16,10 & 3,75 \\
& 60,22 & 10,49 & 13,94 & 22,80 & 6,30 \\
Tanah+pasir+kompos & & & & & \\
UJ-3 & 49,81 & 8,69 & 11,36 & 21,20 & 6,35 \\
UJ-5 & 79,03 & 11,92 & 14,08 & 21,40 & 5,50 \\
BW-1 & 59,79 & 12,50 & 14,19 & 25,75 & 4,20 \\
Unila UK-1 & 56,08 & 11,72 & 14,89 & 15,45 & 4,85 \\
\hline Rata-rata & 58,71 & 10,68 & 13,06 & 20,64 & 4,86 \\
\hline
\end{tabular}

Tabel 4. Pengaruh komposisi media pada jumlah akar pada setek empat klon ubikayu.

\begin{tabular}{|c|c|c|c|c|}
\hline \multirow{2}{*}{ Jenis Media Tanam (m) } & \multicolumn{4}{|c|}{ Klon } \\
\hline & UJ-3 & UJ-5 & BW-1 & Unila UK-1 \\
\hline M1 & $20,00 \mathrm{bc}$ & $\begin{array}{c}\ldots \ldots \ldots \ldots \\
16,50 \mathrm{c}\end{array}$ & $30,50 \mathrm{~b}$ & $41,50 \mathrm{a}$ \\
\hline M2 & $\begin{array}{c}28,00 \mathrm{~b} \\
\text { (a) }\end{array}$ & $\begin{array}{c}44,50 \mathrm{a} \\
\text { (a) }\end{array}$ & $\begin{array}{c}28,50 \mathrm{~b} \\
\text { (a) }\end{array}$ & $\begin{array}{c}26,50 \mathrm{~b} \\
\text { (b) }\end{array}$ \\
\hline BNT 5\% & \multicolumn{4}{|c|}{10,78} \\
\hline
\end{tabular}

Keterangan: Nilai tengah yang diikuti huruf sama tanpa tanda kurung dibaca secara horizontal dan dalam tanda kurung dibaca secara vertikal, menunjukkan tidak berbeda nyata berdasarkan uji BNT 5\%. 
Tabel 5. Pengaruh komposisi media tanam terhadap bobot kering akar pada empat klon ubi kayu.

\begin{tabular}{ccccc}
\hline \multirow{2}{*}{ Jenis Media Tanam $(\mathrm{m})$} & \multicolumn{4}{c}{ Jenis Klon } \\
\cline { 2 - 5 } & UJ-3 & UJ-5 & BW-1 & Unila UK-1 \\
\hline \multirow{2}{*}{ M1 } & $1,03 \mathrm{a}$ & $1,06 \mathrm{a}$ & $1,05 \mathrm{a}$ & $1,08 \mathrm{a}$ \\
& (b) & (a) & (a) & (a) \\
\hline M2 & $1,10 \mathrm{a}$ & $1,05 \mathrm{~b}$ & $1,04 \mathrm{~b}$ & $1,04 \mathrm{~b}$ \\
& (a) & (a) & (a) & (a) \\
\hline BNT 5\% & \multicolumn{5}{c}{0,05} \\
\hline
\end{tabular}

Keterangan: Nilai tengah yang diikuti huruf sama tanpa tanda kurung dibaca secara horizontal dan dalam tanda kurung dibaca secara vertikal, menunjukkan tidak berbeda nyata berdasarkan uji BNT 5\%.

Hasanah (2009) menjelaskan bahwa akar akan tumbuh dengan masuk ke dalam tanah melalui ruang pori tanah. Sesuai dengan penelitian Chairani dkk (2015), bahwa penambahan sekam padi sebanyak 3, 5, dan 7 ton/ha mening-katkan porositas berturutturut sebesar 3\%, 5\% dan 10\%.

Berdasarkan hasil penelitian menunjukkan bahwa adanya interaksi antara komposisi media tanam dan jenis klon yang digunakan pada variabel bobot kering akar (Tabel 5). Bobot kering akar menunjukkan jumlah asimilat fotosintesis yang dialokasikan ke akar. Dalam hal ini faktoryang mempengaruhijumlah asimilat adalah unsur hara yang dibutuhkan tanaman, terutama unsur nitrogen. Unsur nitrogen pada media tanam yang menggunakan kompos mengandung $0.07 \%$ lebih tinggi dibandingkan sekam padi. Sejalan dengan penelitian Yuliawati dkk (2014), bahwa pemberian dosis unsur $\mathrm{N}$ dalam bentuk pupuk urea sebesar $45 \mathrm{~kg}$ atau $50 \%$ dari dosis rekomendasi memberikan hasil bobot kering akar lebih tinggi dibandingkan dosis $22,5 \mathrm{~kg}$ atau $25 \%$ dari dosis rekomendasi pada tanaman alfalfa. Menurut Budiana (2008) unsur N pada media tanam berperan dalam proses fotosintesis yang menghasilkan asimilat kemudian dialokasikan ke akar.

\section{KESIMPULAN}

Berdasarkan hasil penelitian dapat disimpulkan bahwa (1) komposisi media tanam tanah : pasir : sekam padi dan tanah : pasir : kompos menghasilkan pertumbuhan setek tanaman yang sama. (2) Tidak terdapat perbedaan pertumbuhan antara klon UJ-3, UJ5, BW-1 dan Unila UK-1.

\section{UCAPAN TERIMA KASIH}

Penulis mengucapkan terima kasih kepada LPPM Universitas Lampung atas pendanaan penelitian Skema Penelitian Dasar Universitas Lampung tahun 2020 dan semua pihak yang ikut membantu terlaksananya penelitian ini.

\section{DAFTAR PUSTAKA}

Ardian. 2010. Pertumbuhan In vitro Setek Mikro Singkong (Manihot Esculenta Crantz). Jurnal Penelitian Pertanian Terapan 10 (3) :158-163.

Atmawinata, A., D. Irianto, L. Diawati, A. Adlir, Y. Susilo, W. Radjid, Massaruddin, P. J. Ardika, H. Sudrajat, A.S. Indarto, O.V.T. Bona, Solehan, dan D. Kurniawan. 2008. Kedalaman Struktur Industri Yang 
Mempunyai Daya Saing Di Pasar Global. Bappenas. Jakarta. 86 p.

Budiana, N. S. 2008. Memupuk Tanaman Hias. Penebar Swadaya, Jakarta. $88 \mathrm{hlm}$

Chairani, S., Idkham, M. dan Wahyuliana, D. 2015. Analisis Pengolahan Tanah dengan Menggunakan Traktor Roda Empat dan Pemberian Sekam Padi terhadap Perubahan Sifat Fisika dan Mekanika Tanah. Prosiding Seminar Nasional Biotik 2015.

Hakim, B.S. 2013. Simulasi Pengaruh Media Tanam Sekam dan Pupuk Kandang Terhadap Pertumbuhan Tinggi Tanaman Wortel dengan Menggunakan Metode Fuzzy Sugeno Berbasis XL System. Universitas Negeri Maulana Malik Ibrahim. Malang. 82 p.

Handayanto, E., N. Muddarisna, A. Fiqri. 2017. Pengelolaan Kesuburan Tanah. UB Press. Malang. 138-141 p.

Hasanah, U. 2009. Respon Tanaman Tomat (Lycopersicum esculentum Mill) pada Awal Pertumbuhan Terhadap Keragaman Ukuran Agregat Entisol. J. Agroland 16 (2) : 103-109.

Ismayani, N. Kardhinata, E.H. dan Bangun, M.K. 2016. Respon Beberapa Genotipe dan Pelukaan Stek (Pengeratan) terhadap Pertumbuhan Tanaman Ubi Kayu (Manihot esculenta Crantz.) untuk Meningkatkan Produktivitas. Jurnal Agroekoteknologi FP USU 4 (3) : 2028-2033.
Kusuma, A.H., Izzati, M. dan Saptiningsih, E. 2013. Pengaruh penambahan arang dan abu sekam dengan proporsi yang berbeda terhadap permeabilitas dan porositas tanah liat serta pertumbuhan kacang hijau (Vigna radiata $\mathrm{L}$ ). Buletin Anatomi dan Fisiologi.21(1): 1-8.

Lubis, S.T., Rahmawati, N. dan Irmansyah, T. 2017. Pengaruh Zat Pengatur Tumbuh dan Komposisi Media Tanam Terhadap Pertumbuhan Okulasi Ubi Kayu. Jurnal Agroekoteknologi FP USU 5 (1) : 195-201.

Ratnasari, N. 2014. Pengaruh Asal Bahan dan Bentuk Pangkal Batang Terhadap Pertumbuhan Stek Ubi Kayu. Skripsi. Unversitas Jember. Jember.

Roja, A. 2009. Ubi kayu: Varietas dan Teknologi Budidaya. Balai Pengkajian Teknologi Pertanian Sumatera Barat. Sumatera Barat. $15 \mathrm{hlm}$.

Roni, N.G.K. 2015. Tanah Sebagai Media Tanam Bahan Ajar. Fakultas Peternakan Universitas. Udayana. $34 \mathrm{p}$.

Sundari, T. 2010. Petunjuk Teknis Pengenalan Varietas Unggul dan Teknik Budidaya Ubi kayu (Materi Pelatihan Agribisnis bagi $K M P H)$. Balai Penelitian Tanaman Aneka Kacang dan Umbi. Malang. 2-11 p.

Yuliawati, A. Rahayu, N. Rochman. 2014. Pengaruh naungan dan berbagai dosis pupuk urea terhadap pertumbuhan dan produksi vegetatif alfalfa (Medicago sativa L.). Jurnal Pertanian. Vol. 5. No. 1. Hal. 43-51 